Motrivivência Ano XXV, No 41, P. 305-320 Dez./2013

http://dx.doi.org/10.5007/2175-8042.2013v25n41p305

\title{
O CONTEÚDO DAS LUTAS NAS SÉRIES INICIAIS DO ENSINO FUNDAMENTAL: possibilidades para a prática pedagógica da Educação Física escolar
}

\author{
Nathalia Chaves Gomes \\ André Minuzzo de Barros 2 \\ Fernando Paulo Rosa de Freitas ${ }^{3}$ \\ Suraua Cristina Darido 4 \\ Luiz Gustavo Bonatto Rufino 5
}

\section{RESUMO}

As lutas são conteúdos da Educação Física que devem estar presentes na prática pedagógica. Contudo, há ainda lacunas e incompreensões em seu desenvolvimento pedagógico. Assim, por meio de uma revisão de literatura, este estudo objetivou analisar as lutas compreendendo sua importância, bem como apresentando uma forma de classificação. Em um segundo momento, apresentou-se uma proposta de organização curricular das lutas nas séries iniciais do ensino fundamental. Conclui-se ser importante compreender as lutas enquanto conteúdos das aulas de Educação Física propondo uma organização dos conteúdos que pode contribuir com a apropriação crítica dessa manifestação da cultura corporal de movimento.

Palavras-chave: Lutas; Prática pedagógica; Organização dos conteúdos.

1 Especialista em Educação Física/UNICAMP. Professora da UNESP. Rio Claro/São Paulo, Brasil. E-mail: nathichaves@hotmail.com

2 Doutorando em Desenvolvimento Humano e Tecnologias - UNESP. Rio Claro/São Paulo, Brasil.

E-mail: andreminuzzo@terra.com.br

3 Mestre em Ciências da Motricidade Humana - UNESP. Rio Claro/São Paulo, Brasil.

E-mail: fer_edfis@hotmail.com

4 Doutorado em Psicologia Escolar e do Desenvolvimento Humano - USP. UNESP/Rio Claro, Brasil.

E-mail: surayacd@rc.unesp.br

5 Mestre pelo Programa Interdisciplinar de Desenvolvimento Humano e Tecnologias. UNESP/ Rio Claro, Brasil. E-mail: gustavo_rufino_6@hotmail.com 


\section{INTRODUÇÃO}

De acordo com os Parâmetros Curriculares Nacionais (PCN/BRASIL, 1998) nas práticas corporais, o movimento humano é sistematizado, ressignificado e transmitido de geração a geração, resultando em um patrimônio histórico-cultural de práticas ou manifestações corporais que são denominadas de cultura corporal de movimento. Para esse documento à Educação Física na escola deve ser incumbida da possibilidade de introduzir e integrar os alunos na esfera da cultura corporal de movimento, de modo a contribuir com a formação do cidadão, que vai tanto produzi-la quanto reproduzi-la, bem como transformá-la.

Diversas são as manifestações corporais que fazem parte desse amplo patrimônio, como os esportes, as danças, as ginásticas, os jogos, as atividades físicas de aventura, as práticas circenses, as lutas, entre outras. É preciso permitir ao aluno o contato e vivências significativas com esses conteúdos, possibilitando-os articular reflexões críticas sobre estas práticas e sobre o mundo em que vivem.

No entanto, devido à amplitude de possibilidades apresentadas pelas práticas corporais, há ainda dificuldades no desenvolvimento pedagógico de algumas delas, de modo que a prática pedagógica da Educação Física escolar, muitas vezes, fique ainda restrita ao ensino de algumas modalidades esportivas coletivas (BETTI; ZULIANI, 2002; BRACHT et al., 2002; BRASIL, 1998; DARIDO et al., 1999; RANGEL-BETTI, 1999).

No caso das lutas, entende-se que elas são uma das manifestações da cultura corporal de movimento, de modo que também podem ser produzidas, reproduzidas, transformadas e usufruídas pelos alunos ao longo das aulas de Educação Física. Dessa forma, representam um importante conteúdo que deve fazer parte dos processos de ensino e aprendizagem ao longo dos ciclos de escolarização (SOARES et al., 1992).

Contudo, Rufino e Darido (2013) apontam que o conteúdo das lutas ainda é pouco explorado por grande parte dos professores de Educação Física escolar. Tal fato decorre por diversos fatores como preconceito com relação a esses conteúdos, falta de materiais e vestimentas adequadas, incitação sobre questões relacionadas à violência, entre outros (CARREIRO, 2005; BRARROS e GABRIEL, 2011).

Os autores acreditam, por outro lado, que a maior dificuldade está na insegurança em relação ao tratamento desse tema pelo fato dos professores considerarem erroneamente que é necessário ser ou ter sido um praticante de alguma modalidade para desenvolvê-lo na escola.

Outra questão que merece destaque e que dificulta o ensino das lutas na escola em diversos contextos refere-se à defasagem na formação profissional. Tal fato levou Del Vecchio e Franchini (2006) a alertarem para diversas lacunas no que corresponde ao não ensino das lutas no Ensino Superior ou então a restrição desse ensino, decorrido do tratamento de somente uma ou outra modalidade (como judô e capoeira, por exemplo) nos currículos dos cursos de formação profissional em Educação Física.

Contribuindo ainda mais com a lacuna na compreensão das lutas nas aulas de Educação Física está a pouca produção acadêmica a esse respeito. Correia e Franchini (2010) afirmam haver carência de publicações sobre lutas, artes marciais e modalidades esportivas de combate no 
Brasil, principalmente os estudos de caráter aplicado. Os conhecimentos sistematizados sobre as múltiplas dimensões dessas práticas corporais são fundamentais para subsidiar os professores em suas práticas, tanto na formação inicial como na continuada, evidenciando a importância de ampliar a produção a esse respeito.

Esses dados vão de encontro com o que Drigo (2007) salienta ao constatar a pouca produção acadêmica sobre as lutas e artes marciais. O autor enfatiza ainda a escassez de produções em uma perspectiva pedagógica e sócio-cultural, uma vez que a grande maioria dos estudos que existem abordam as áreas da fisiologia e treinamento de atletas (subárea da biodinâmica).

Tal fato é corroborado por Nascimento $(2008$, p. 2) quando o autor indica que a temática das lutas "necessita de estudos e sistematizações que subsidiem o seu trato pedagógico efetivo na escola". Ainda para o autor, a questão da sistematização do conteúdo das lutas na Educação Física escolar é ainda uma grande carência desta área. Ou seja, a despeito das poucas publicações a respeito das lutas enquanto conteúdos da Educação Física escolar, é necessário ainda compreender formas de organizar sistematicamente a abordagem pedagógica desse conteúdo ao longo dos processos de ensino e aprendizagem.

Sendo assim, buscando avançar nas lacunas ainda existentes e corroborar a necessidade de desenvolvimento de propostas de organização curricular para o trato pedagógico das lutas durante as aulas de Educação Física, este trabalho objetivou, por meio de uma revisão de literatura, em um primeiro momento, analisar as lutas como conteúdos da Educação Física escolar, compreendendo sua importância, bem como apresentando uma forma de classificação. Além disso, em um segundo momento, procurou-se apresentar uma proposta de organização curricular das lutas nas séries iniciais do ensino fundamental.

\section{PROCEDIMENTOS METODOLÓGICOS}

Para o presente estudo realizou-se uma revisão de literatura acerca das temáticas referentes à inserção do conteúdo das lutas na Educação Física escolar. A revisão de literatura compreende uma busca sistemática pelo que já foi produzido - e publicado - em alguma(s) determinada(s) área(s) de investigação, conforme sugerem Thomas, Nelson e Silverman (2007).

Essa técnica é importante por nos permitir uma imersão no estado da arte de uma determinada área. Sendo assim, procurou-se averiguar as compreensões das lutas no âmbito da Educação Física. Para isso, partimos das considerações apresentadas por Correia e Franchini (2010), os quais ao analisarem 11 periódicos nacionais entre os anos de 1998 até 2008 encontraram que apenas $2,93 \%$ dos trabalhos abordavam as lutas. Destes, somente $10,7 \%$ relacionavam-se com o âmbito pedagógico.

Buscamos ampliar a busca acerca da produção científica sobre as lutas trazendo uma análise qualitativa sobre os artigos produzidos no que corresponde à temática pedagógica. Para isso, compreendemos o período entre os anos de 2008 e 2012, buscando atualizar os dados de Correia e Franchini (2010) nos mesmos periódicos apresentados pelos autores, a saber: Conexões, Corpoconsciência, Movimento, Motriz, Revista Brasileira de Ciências do Esporte, Revista Brasileira de Ciência e 
Movimento, Revista Brasileira de Cineantropometria e Desempenho Humano, Revista da Educação Física, Revista de Educação Física, Revista Mineira de Educação Física e Revista Brasileira de Educação Física e Esporte. Acrescida desses periódicos inserimos na análise as revistas Motrivivência e Pensar a Prática, que também apresentam produções relacionadas às lutas, totalizando 13 revistas científicas analisadas.

Para as análises, foram abordados os seguintes tópicos de discussão: Lutas: algumas definições; As lutas na escola: motivos, importância e significados; O conteúdo das lutas na escola: possível classificação; As lutas nas séries iniciais do ensino fundamental: proposta de organização curricular. Cada tópico será discutido a seguir.

\section{Lutas: algumas definições}

As definições sobre lutas podem contribuir com maiores compreensões acerca dessas práticas corporais. Contudo, não há consensos na literatura uma vez que transitam na área diversas acepções distintas, algumas limitando a compreensão apenas ao que corresponde ao combate e à oposição entre duas pessoas, outras trazendo sentidos mais filosóficos e holísticos ao entendimento dessas práticas. Em muitos contextos o verbo "lutar" apresenta diversos significados.

Segundo Mazzei (2006) a palavra luta vem do latim: lucta. Ela pode ser definida como combate entre duas ou mais pessoas, com ou sem armas, mas também pode ter um sentido mais abrangente e estar ligado ao esforço de um ser em alcançar um objetivo, conflito entre doutrinas ou oposição entre forças materiais ou morais.
Para Rufino (2012a, p. 17): "a palavra 'lutar' pode conter em si uma série de significados que variam de acordo com o contexto. Luta-se pela vida, por objetivos pessoais, pela terra, com um oponente em alguma prática esportiva, e assim por diante". Ao abordar especificamente as lutas enquanto práticas corporais, esse mesmo autor destaca que:

Em termos de esportivização, as lutas compreendem uma série de práticas, com diferenças e similaridades entre si, na qual possuem objetivos distintos. Há lutas em que não se pode tocar no outro, em que só valem golpes com os braços (punhos), lutas de agarramento, lutas que se utilizam de técnicas à distância, lutas com artefatos, numa infinidade de práticas (RUFINO, 2012a, p. 17).

Sendo assim, embora difícil de precisar uma vez que a histórica não decorre por processos lineares, as lutas como as conhecemos, representam uma forma que as sociedades encontraram para superar as adversidades de seu meio físico. Com o passar do tempo, foi sistematizada e com aplicações práticas nas guerras, em eventos diversos, nos esportes, entre outros.

Os PCN (BRASIL, 1998) trazem uma definição de lutas partindo das ações procedimentais originárias dessas práticas, mas também compreendendo valores e atitudes circunscritos. Para esse documento oficial as lutas são definidas como sendo disputas em que os oponentes devem ser subjugados com técnicas e estratégias de desequilíbrio, imobilização ou exclusão de um determinado espaço na combinação de ações de ataque e defesa. Os parâmetros destacam ainda que as lutas podem ser caracterizadas por uma regulamentação específica que busca punir atitudes de violência e deslealdade. 
Bechara (2004, p. 73), por sua vez, aponta que as lutas "são manifestações culturais da Cultura Corporal que reproduzem as formas históricas de enfrentamento (...) e de preparação para o combate, totalmente ineficientes no mundo atual comandado pela tecnologia, porém cheias de tradições e formas simbólicas de combate". O autor não apresenta explicações, no entanto, sobre os motivos de considerar as ações das lutas ineficientes no mundo atual.

Para a Proposta Curricular do Estado de São Paulo (SÃO PAULO, 2008) as lutas apresentam em suas origens, características atribuídas à sobrevivência, ao exercício físico, ao treinamento militar, à defesa e ao ataque pessoal, além das implicações das tradições culturais, religiosas e filosóficas. Com o surgimento de outras necessidades e o desenvolvimento de novas técnicas, o ser humano atribuiu outros significados às lutas. Atualmente há um amplo processo de esportivização de muitas modalidades bem como de espetacularização, haja vista a projeção atual dos eventos de Mistura de Artes Marciais (ou Artes Marciais Mistas), da sigla em inglês MMA (PAIVA, 2009).

Em Gomes (2008) e Gomes et at. (2010) encontramos uma definição a qual compreende as lutas enquanto práticas corporais imprevisíveis que são caracterizadas por apresentar determinado nível de contato entre os participantes, bem como possibilitar a execução de ações ofensivas e defensivas realizadas simultaneamente. Estes autores salientam ainda que o objetivo das lutas é mútuo, sobre um alvo móvel, personificado no oponente.

Para tais definições Gomes (2008) e Gomes et al. (2010) buscam contemplar os princípios condicionais do modelo proposto por Bayer (1994) para os esportes coletivos, adaptando tais pressupostos para as lutas. Para isso, estas práticas corporais são caracterizadas pelos seguintes aspectos: contato proposital; fusão ataque/defesa; imprevisibilidade; oponente/alvo e regras (GOMES, 2008; GOMES et al., 2010).

Independente da modalidade ou especificidade da luta proposta, tais princípios salientados anteriormente são condições indispensáveis para que possamos classificar uma prática como sendo relacionada às lutas. Ou seja, tais princípios revestem as práticas das lutas de características próprias, permitindo-nos diferenciá-las das demais práticas corporais. Por isso, a compreensão de tais características é fundamental para que haja subsídios que possam permitir aos professores ensinar tais manifestações da cultura corporal de movimento na escola, durante as aulas de Educação Física.

Rufino e Darido (2011) trazem para a pauta a busca pela compreensão se as lutas são ou não são esportes. Os autores concluem que algumas práticas associadas às lutas passaram por um processo de esportivização, enquanto que outras não. Além disso, os autores ressaltam que ora estas práticas podem ser consideradas como esportivas, caso se incluam nas definições da sociologia do esporte, ora podem ser compreendidas como jogos e brincadeiras, por exemplo, quando vinculadas às aulas de Educação Física na escola.

A partir de tais apontamentos acreditamos que é possível convergir propostas de compreensão das lutas nos contextos escolarizados, buscando romper paradigmas que outrora relacionaram tais práticas com aspectos vinculados à violência ou falta de respeito entre os participantes. Portanto, é preciso ter clareza do universo plural e multifacetado relacionado às lutas (CORREIA; FRANCHINI, 2010). 
Corroboramos com Rufino (2012a, p. 17) quando o autor arremata: "dessa forma, antes de pretender encontrar um conceito 'rígido e fechado' ao termo das 'lutas', é evidente que, por tudo isso, o ser humano luta há muito tempo, desde as épocas mais remotas de sua existência".

Ou seja, mais do que buscar por definições a priori acerca da pluralidade de significados adjacentes às lutas, é fundamental compreender seu processo de construção histórica, fato que se torna preponderante quando relacionamos tais práticas como pertencentes à cultura corporal de movimento. A partir de tais relações, podemos construir um panorama que contribua com a prática pedagógica na Educação Física escolar, dando subsídios para o desenvolvimento de propostas de implementação das lutas na escola. No próximo tópico, buscaremos enfocar a importância das lutas na escola e como elas podem se inserir ao longo dos processos de ensino e aprendizagem na Educação Física escolar.

\section{As lutas na escola: motivos, importância e significados}

Entendemos que, a escola, desde seu primeiro nível de ensino, deve ter como objetivo que os alunos se apropriem de saberes que irão contribuir para a sua formação enquanto indivíduos que venham a exercer a cidadania com valores democráticos, de forma crítica e autônoma, em busca da construção de uma sociedade mais justa e igualitária.

Palma Filho (1998) afirma que a escola torna possível a existência do cidadão, na medida em que cumpre a sua função de viabilizar o acesso da população ao conhe- cimento socialmente produzido e acumulado historicamente, independentemente da condição social do aluno, devendo ir além da mera transmissão, cópia ou reprodução do conhecimento. O autor ainda aponta que a Educação escolar não é condição suficiente, mas é condição necessária para desabrochar a cidadania, com vistas à formação do sujeito, num contexto de direitos e deveres.

Diante disso e considerando que a Educação Física está inserida num contexto maior, que é a Educação escolar, fica evidente a sua participação na formação da cidadania e a necessidade que isso seja considerado na elaboração e concretização da prática pedagógica.

Neste contexto, as lutas representam uma das práticas integrantes da cultura corporal de movimento, cujo tratamento pedagógico deverá ampliar os conhecimentos relacionados a conceitos, procedimentos e atitudes dos alunos, para que possam fazer opções mais conscientes e autônomas (BRASIL, 1998).

Ao conhecer as lutas em diversos aspectos (políticos, econômicos, sociais, históricos, estéticos, fisiológicos etc.), os alunos poderão se apropriar de elementos que contribuirão com a construção crítica de conhecimentos, valores, atitudes, fatos e procedimentos que auxiliarão na ampliação de suas visões de mundo. No caso das lutas, é possível além de vivenciar diversas práticas corporais, compreender o enfoque apontado pelas mídias, diferenciando-as dos contextos violentos, possibilitando a tomada de decisões sobre opções mais conscientes para sua vida cotidiana, entendendo estas práticas corporais como possibilidades de lazer, saúde, rendimento, comunicação, expressão corporal, entre outras. 
No entanto, é ainda corriqueiro o estabelecimento de associações errôneas das lutas com questões relacionadas à incitação à violência, às brigas, entre outras questões (BARROS; GABRIEL, 2011; CARREIRO, 2005; RUFINO; DARIDO, 2013). Tais relações estão revestidas não apenas de preconceitos, mas de concepções limitadas e pautadas em distorções sobre o que de fato as lutas podem significar para a prática pedagógica a partir de sua vinculação como uma das manifestações da cultura corporal de movimento.

No caso especificamente das crianças, Olivier (2000) aponta que desde cedo podemos constatar nas escolas jovens disputando objetos ou territórios, e que isso faz parte de seu processo de desenvolvimento para aprender a regular conflitos. Para esse autor, tais processos são formas de comunicação e expressão pela qual a criança possa reagir a um estresse, a uma frustração, provocação, entre outros.

Jogos e brincadeiras envolvendo elementos das lutas podem contribuir para que a criança aprenda a gerir e a controlar a complexidade das relações violentas no interior do grupo social, tal como apontam Rufino e Darido (2011). Portanto, as lutas apresentam notável presença no universo infantil e podem ser tratadas desde as séries iniciais do ensino fundamental, permitindo que a criança diferencie lutas e brigas. Para isso é fundamental que elas compreendam os sentidos e significados de tais práticas e como elas se distinguem das brigas e outras atitudes pautadas pela ótica da violência.

Outro fator fundamental no qual as lutas estão presentes, sobretudo na infância, refere-se às relações que estas práticas estabelecem com as mídias, que, por vezes, têm grande responsabilidade pela associação com contextos de violência. Desde as séries iniciais do ensino fundamental é preciso contextualizar pedagogicamente os desenhos animados, brinquedos, jogos de cartas e tabuleiros, mangás, histórias em quadrinhos, elementos que fazem parte do universo infantil.

Por essas e outras razões as lutas devem estar relacionadas às aulas de Educação Física, desde os mais tenros anos de escolarização. Dessa forma, é possível ressignificar visões ainda dicotomizadas e permeadas pela ótica do preconceito para com estas práticas. Ademais, a diversificação de conteúdos propicia uma ampliação da apropriação da cultura corporal de movimento, de modo que tal processo deve ocorrer já nas séries iniciais do ensino fundamental. Para que as lutas possam efetivamente fazer parte da prática pedagógica, apresentaremos, na sequência, algumas possibilidades de classificação.

\section{O conteúdo das lutas na escola: possível classificação}

As práticas corporais, em sua ampla magnitude de formas, sentidos e manifestações, para serem ensinadas na escola devem ser adaptadas aos objetivos e possibilidades da instituição escolar. De acordo com González e Fensterseifer (2010) a Educação Física tradicionalmente pouco tem sido pensada dentro de uma perspectiva educacional pautada na compreensão de leitura de mundo, o que passa, impreterivelmente, pela necessidade de entendimento do que significa ser um componente curricular obrigatório no sentido de matéria escolar. Nesse sentido, os autores salientam: 
Nessa linha, a EF escolar, na condição de disciplina, tem como finalidade formar indivíduos dotados de capacidade crítica em condições de agir autonomamente na esfera da cultura corporal de movimento e auxiliar na formação de sujeitos políticos, munindo-os de ferramentas que auxiliem no exercício da cidadania (GONZÁLEZ; FENSTERSEIFER, 2010, p. 12).

Ainda para esses autores, é necessário que cada componente curricular se constitua enquanto um elemento que contribua com a ampliação das visões de mundo das pessoas. A Educação Física escolar deve, por conseguinte, corroborar com tal intencionalidade de modo que as diversas manifestações da cultura corporal de movimento possibilitam.

No caso das lutas, a literatura tem apontado algumas formas de abordagem teórico-metodológica buscando outras maneiras de compreensão que não se limitem, ou ao menos não redundem, no ensino de apenas algumas vivências de uma ou poucas modalidades em específico (RUFINO, 2012b; GOMES et al., 2010; GOMES, 2008; BREDA et al., 2010).

Para se pensar em formas de ensino das lutas que vão além da dependência de apenas uma ou outra modalidade é preciso que se compreendam as unidades didáticas enquanto processos de vivência, reflexão, ação e interpretação sobre essas práticas. Nesse contexto é necessário compreender elementos que possam ser concebidos como conhecimentos que farão parte do conteúdo das lutas na escola.

De acordo com os PCN (BRASIL, 1998), há alguns objetivos da prática das lutas na escola, os quais podem ser sistematizados da seguinte maneira:
- Compreensão por parte do educando do ato de lutar (por que lutar, com quem lutar, contra quem ou contra o que lutar);

- Compreensão e vivência de lutas no contexto escolar (lutas versus violência; vivência de momentos para a apreciação e reflexão sobre as lutas e a mídia);

- Análise dos dados da realidade positiva das relações positivas e negativas com relação a prática das lutas e a violência na adolescência (luta como defesa pessoal e não para "arrumar briga").

Ainda para esse documento de caráter oficial o processo de ensino e aprendizagem das lutas requer, entre outros aspectos, a vivência de situações que envolvam perceber, relacionar e desenvolver as capacidades físicas e habilidades motoras presentes nas lutas praticadas na atualidade; vivência de situações em que seja necessário compreender e utilizar as técnicas para a resolução de problemas em situações específicas - tais como as técnicas e táticas de ataque e defesa - e também vivências de atividades que envolvam as lutas, dentro do contexto escolar (BRASIL, 1998).

Tais proposições apresentam a conjuntura de ilustrar algumas possibilidades de intervenção pedagógica, entretanto, não aprofundam em termos de quais conhecimentos devem ser ensinados, bem como não demonstram uma organização curricular para o ensino das lutas ao longo dos diversos ciclos de escolarização.

A busca por uma forma de classificação introduz a perspectiva de ampliação das compreensões acerca dessas manifestações corporais. Nesse contexto, podemos encontrar alguns critérios para a 
seleção/classificação das lutas na escola, tais como: compreensões dos objetivos de um enfrentamento, qual o tipo de contato entre oponentes, quais as ações motoras desenvolvidas, a distância entre os oponentes, o tipo de meta no enfrentamento, entre outras. Porém esses agrupamentos ao mesmo tempo em que unem as lutas pelo que possui em comum, também as separam por suas diferenças (GOMES, 2008).

Para Espartero (1999) a classificação das lutas, denominado pelo autor de esportes de luta, promove uma organização de elementos ou categorias de acordo com um determinado critério, que permite estabelecer uma diferenciação entre eles, o que facilitaria o ensino e a escolha do mais adequado a ser ensinado. As orientações teórico-metodológicas do Estado de Pernambuco (2008) contribuem com essa perspectiva ao assinalar:

A luta, assim como os outros temas da cultura corporal, precisa ser abordada levando em consideração, em primeiro lugar, os aspectos de organização da identificação e da categorização dos movimentos de combate corpo-a-corpo. Depois, abordando a iniciação da sistematização desses movimentos, a partir da compreensão do sentido/significado de cada uma de suas formas. Por fim, chegando até a ampliação dessa sistematização, de maneira que sejam compreendidas as técnicas mais aprimoradas e sejam criadas outras formas de combate (PERNAMBUCO, 2008, p. 26).

Gomes (2008) considerando as ideias de Bayer (1994) à luz das classificações pesquisadas, apresenta a classificação organizada a partir das distâncias existentes entre os oponentes, bem como às ações empregadas em cada uma dessas distâncias, perspectiva corroborada por outros autores, tais como Breda et al. (2010) e Rufino (2012b). O quadro a seguir ilustra tal proposição.

Quadro 1: Os grupos de aproximação das Lutas - Adaptado de Gomes (2008)

\begin{tabular}{|c|c|c|}
\hline Curta Distância & Média Distância & Longa Distância \\
\hline Desequilibrar & Tocar & Tocar (intermediado por \\
Rolar & implementos) \\
Projetar & Golpear (Mãos, braços, \\
Cair & cotovelos, pernas, joelhos, \\
Controlar & pés, etc.) & Manipular (implemento) \\
\hline
\end{tabular}

Com relação às ações de curta distância destaca-se que elas possuem pouco espaço entre os oponentes e para a realização das técnicas e alcance dos objetivos da luta é necessário que os praticantes se coloquem em contato direto (contato como um meio para o fim). Como habilidades específicas da curta distância estão ações como segurar, pegar, projetar, rolar, cair, desequilibrar, que demonstram a necessidade do contato direto entre os oponentes e alunos na prática dessas modalidades.

As ações de média distância empreendem um espaço médio, ou moderado entre os envolvidos no qual permite a aproximação em situações de ataque entre os oponentes, pois a intenção e o propósito ofensivo vão determinar a distância entre os 
lutadores. Os golpes caracterizam o contato e não dependem dele para acontecer como na curta distância (o contato é um fim e não o meio). Na média distância estão presentes os chutes, socos e as sequências combinadas.

Finalmente, as ações de longa distância são definidas pela presença de um implemento e, por isso, deve haver uma distância maior entre os oponentes para que os mesmos possam manipular de forma adequada esse implemento, fazendo com que o contato entre eles seja por meio de uma espada, por exemplo. Na longa distância há ações como as empunhaduras, habilidades manipulativas e posturas.

Para se desenvolver tais perspectivas na escola, ao longo das aulas de Educação Física, os professores podem lançar mão de uma série de estratégias teórico-metodológicas. Nessa visão, os jogos podem ser compreendidos enquanto elementos que proporcionam potenciais de ensino. Para Olivier (2000) os jogos podem ser compreendidos enquanto uma simplificação na abordagem de lutar, no qual os alunos devem desempenhar papéis que serão previamente definidos pelo professor (o jogador ataca ou defende, imobiliza ou livra-se, desequilibra ou tenta manter o equilíbrio), ao invés de desempenhá-los simultaneamente. Tais perspectivas, ao menos ao longo das séries iniciais do ensino fundamental facilita a aprendizagem e conscientização quanto os elementos das lutas (RUFINO; DARIDO, 2011).

O autor ainda classifica as lutas dentro de seis categorias, as quais podem estar permeadas pela classificação das distâncias: jogos de rapidez e de atenção; jogos de conquista de objetos; jogos de conquista de territórios; jogos de desequilibrar; jogos para reter, imobilizar e livrar-se; jogos para combater (OLIVIER, 2000). Esses jogos abrangem ações motoras fundamentais que as crianças são capazes de realizar nas atividades de oposição. É possível ainda que os professores incluam outros elementos nas unidades didáticas relacionadas às lutas nas séries iniciais, desde que haja clareza dos objetivos pretendidos, bem como do nível desenvolvimento dos alunos.

Reconhecemos que as classificações apresentadas não contemplam a diversidade de lutas existentes e que tão adoção, como toda tomada de decisão, implica em uma seleção de procedimentos e conhecimentos (FORQUIN, 1993). Contudo, tal perspectiva permite ilustrar possibilidades concretas de contextualização didática das lutas na escola haja vista, dentro de outras questões, a grande amplitude de práticas existentes relacionadas às lutas (CORREIA; FRANCHINI, 2010), bem como às perspectivas de formação profissional atualmente em voga (DEL VECCHIO; FRANCHINI, 2006).

Acreditamos ainda que nos anos iniciais do ensino fundamental é possível aprender as lutas por meio de jogos que enfatizem os elementos das lutas. Sendo assim, modificamos e adaptamos a classificação de jogos de Olivier (2000), tratando dos elementos de lutas que prevalecem nos jogos de combate, resultando na seguinte classificação:

- Jogos de esquivar: consiste em jogos de ações de desvio dos ataques desferidos, sendo que é preciso alternar os papéis de quem ataca e de quem defende, evitando o contato com o adversário;

- Jogos de imobilizar: são jogos em que há a necessidade de contato para se chegar a ações de imobilização e de saídas ou fugas de 
imobilização. Os papéis podem ser combinados, ou seja, tanto se pode imobilizar quanto escapar, ou separados, quando apenas um trabalha imobilizando enquanto $o$ outro somente tenta escapar;

- Jogos de conquistar território: são jogos que consistem em conquistar, defender ou excluir o adversário de um determinado espaço. Implicam aproveitamento e diversificação das ações desequilibradoras para chegar a seus fins. È preciso também puxar, carregar, empurrar, fazer virar, esquiva-se, desviar, resistir. O contato é quase sempre inevitável;

- Jogos de desequilibrar: consiste em jogos que tem o objetivo de desfazer os apoios do adversário no solo, podendo ser finalizado com o toque de determinada parte do corpo no solo ou exclusão de determinado espaço ou marca. Os papéis de ataque e defesa também podem ser, ora alternativos, ora simultâneos.

Consideramos que é possível abordar as lutas nas séries iniciais do ensino fundamental por meio de outras estratégias didático-metodológicas que possibilitem apropriações críticas de mais essa manifestação da cultura corporal de movimento aos alunos. Contudo, as propostas preconizadas no presente texto podem contribuir com a fundamentação teórica, bem como com subsídios práticas que contribuam efetivamente com o ensino das lutas na escola.

\section{As lutas nas séries iniciais do ensino funda- mental: proposta de organização curricular}

Além da proposta de classificação das lutas que corrobore com a prática pedagógica de professores de Educação Física nas séries iniciais do ensino fundamental, o presente trabalho objetivou também ilustrar uma proposta de organização curricular para esse conteúdo. Em princípio, reconhecemos que essa é uma possibilidade entre outras que podem ser elaboradas, fato que deve fazer parte das ações curriculares de seleção e organização dos conteúdos (FORQUIN, 1993), ao longo dos processos de ensino e aprendizagem das aulas de Educação Física. Nossa proposta pode ser visualizada a seguir. 
Quadro 2: Organização curricular sobre o conteúdo das lutas ao longo das séries iniciais do ensino fundamental

\begin{tabular}{|c|c|c|c|c|c|}
\hline & $1^{\circ}$ ANO & $2^{\circ}$ ANO & $3^{\circ}$ ANO & $4^{\circ}$ ANO & $5^{\circ}$ ANO \\
\hline TEMA 1 & $\begin{array}{l}\text { O que são } \\
\text { lutas? } \\
2 \text { aulas }\end{array}$ & $\begin{array}{c}\text { Revisão } \\
\text { conteúdos já } \\
\text { estudados nos } \\
\text { anos anteriores }\end{array}$ & $\begin{array}{c}\text { Revisão } \\
\text { conteúdos já } \\
\text { estudados nos } \\
\text { anos anteriores }\end{array}$ & $\begin{array}{c}\text { Revisão } \\
\text { conteúdos } \\
\text { já estudados } \\
\text { nos anos } \\
\text { anteriores }\end{array}$ & $\begin{array}{c}\text { Revisão } \\
\text { conteúdos já } \\
\text { estudados nos } \\
\text { anos anteriores }\end{array}$ \\
\hline TEMA 2 & $\begin{array}{c}\text { Diferenciação } \\
\text { de lutas e } \\
\text { briga }\end{array}$ & $\begin{array}{l}\text { Elementos das } \\
\text { lutas: jogos de } \\
\text { lutas de } \\
\text { desequilibrar e } \\
\text { conquistar } \\
\text { território } \\
4 \text { aulas }\end{array}$ & $\begin{array}{l}\text { Elementos das } \\
\text { lutas: criação e } \\
\text { transformação }\end{array}$ & $\begin{array}{c}\text { Origem e } \\
\text { Possibilidades } \\
\text { de Lutas }\end{array}$ & $\begin{array}{l}\text { Conhecendo } \\
\text { as Lutas }\end{array}$ \\
\hline TEMA 3 & $\begin{array}{l}\text { Elementos } \\
\text { das lutas: } \\
\text { jogos de lutas } \\
\text { de esquivar e } \\
\text { imobilizar } \\
3 \text { aulas }\end{array}$ & $\begin{array}{l}\text { Lutas X desenho } \\
\text { animado (Mídia) } \\
4 \text { aulas }\end{array}$ & $\begin{array}{c}\text { Lutas e Mídia } \\
\text { (filmes e jogos } \\
\text { virtuais) } \\
2 \text { aulas }\end{array}$ & $\begin{array}{c}\text { Classificação } \\
\text { das lutas }\end{array}$ & $\begin{array}{c}\text { Técnicas e } \\
\text { estratégias de } \\
\text { ações de } \\
\text { ataque e defesa } \\
4 \text { aulas }\end{array}$ \\
\hline $\begin{array}{c}\text { Total de } \\
\text { aulas }\end{array}$ & 8 aulas & 8 aulas & 8 aulas & 8 aulas & 8 aulas \\
\hline
\end{tabular}

Partimos do ponto de partida apresentado por Nascimento e Almeida (2007) que salientam que a inserção das lutas na escola está atrelada à concepção de Educação Física vinculada à perspectiva da cultura corporal de movimento, ou seja, enquanto elementos da cultura, estas manifestações corporais devem fazer parte do processo educativo, não sendo necessário ao professor ser especialista em lutas, embora ele deva compreender alguns dos condicionantes e características dessas práticas para melhor ensiná-las.
Podemos sistematizar a proposta de abordagem da manifestação corporal das lutas de Nascimento e Almeida (2007) a partir das dimensões dos conteúdos: dimensão conceitual, dimensão procedimental e dimensão atitudinal. Em cada uma dessas dimensões há proposições distintas que se relacionam buscando propiciar possibilidades de ensino e aprendizagem na escola.

Na dimensão conceitual é necessário que os alunos apropriem-se dos elementos que constituem as lutas, como histórico, rituais, crenças e principais regras. Tais fatos 
podem ser realizados por meio de trabalhos de pesquisa, permitindo aos alunos aprofundarem seus conhecimentos sobre as lutas, tendo em vista que, muitas vezes, as compreensões sobre lutas advindas do senso comum são superficiais e carregam grande "dose" de preconceito, atribuindo-lhes o imaginário de práticas violentas.

Já na dimensão procedimental, a ênfase recai sobre os jogos de lutas, como já foi ilustrado anteriormente. Dos jogos de lutas que podem ser realizados em aula, destacam-se o cabo de guerra, briga de galo, exclusão de espaço com ombro, mãos, conquista da quadra do oponente e conquista de objetos com oposição. Devem ser incorporados também nos jogos de lutas a criação de regras e novos jogos propostos pelos alunos, no qual eles estabelecem o nome da luta, o modo de jogar/objetivo, as regras, proibições e estratégias.

Finalmente, na dimensão atitudinal deve ser desenvolvido nos jogos criados/ adaptados pelos alunos a intenção de prevenir atitudes de deslealdade por meio das proibições contidas em seus jogos, para demonstrar o respeito, à ética, ao esporte e inibição da violência.

Além disso, é preciso que os alunos adotem critérios para saber analisar, avaliar e criticar situações de exclusão nas aulas de Educação Física, contribuindo, desta forma, para a construção do respeito às diversidades e individualidades dos sujeitos que fazem parte de cada contexto. Nessa perspectiva, Olivier (2000) considera que as lutas são um conteúdo rico para se desenvolver atividades que busquem a diminuição da indisciplina na escola, embora reconheçamos que a dimensão axiológica de valores e atitudes devem permear todas as disciplinas, bem como a cultura escolar como um todo.

A partir das considerações propostas no presente estudo, apontamos a importância de se compreender de modo mais apropriado o processo de organização curricular do conteúdo das lutas ao longo das aulas de Educação Física. Nesse contexto, apresentamos uma proposta de organização baseadas em 8 aulas por ano, bem como de temáticas para serem ensinadas ao longo das séries iniciais do ensino fundamental, baseadas nas dimensões dos conteúdos: conceitual, procedimental e atitudinal.

Essa é uma possibilidade dentre outras que podem ser realizadas. Considera-se, no entanto, fundamental que haja uma organização sequencial dos conteúdos a serem ensinados ao longo das diversas séries escolares de modo que a Educação Física possa ser reconhecida, de fato, com a importância de um componente curricular obrigatório, indo além da perspectiva do "exercitar-se para", criticada por González e Fensterseifer (2010).

\section{CONSIDERAÇÕES FINAIS}

As lutas, enquanto manifestações da cultura corporal de movimento, são um conteúdo relevante que deve ser desenvolvido nas aulas de Educação Física do ensino fundamental, desde seus anos iniciais. Por isso, devem ser produzidas, transformadas, usufruídas e ressignificadas de acordo com as diferentes intencionalidades do processo educativo.

Por questões didáticas, defendemos a necessidade de uma organização para o ensino dos diversos conteúdos escolares. Diante do propósito deste estudo e da carência de publicações neste sentido na área da 
Educação Física sobre lutas, apresentamos uma possibilidade de tratamento de temas e subtemas a serem abordados em cada um dos anos das séries iniciais do ensino fundamental, que são adequados às diversas características dos alunos, favorecendo assim a apropriação de tais conhecimentos, bem como o alcance dos objetivos de uma educação preocupada com a formação para a cidadania.

Enquanto proposta de organização curricular, buscamos apresentar possibilidades para a prática pedagógica das lutas nas séries iniciais do ensino fundamental. Para isso, nos valemos da necessidade de compreender as funções sociais da Educação Física à luz de uma prática permeada por intencionalidades educativas claramente definidas, buscando valorizá-la enquanto componente curricular de importância fundamental ao processo educativo.

Nesse ensejo as lutas, bem como as propostas de organização pedagógica desse conteúdo e dos processos de ensino e aprendizagem relacionados são mais um elemento que compõe a complexidade de relações desenvolvidas. Dessa forma, tais ações devem ser valorizadas em prol de uma prática pedagógica crítica, reflexiva e que ofereça subsídios para a busca pela autonomia e ampliação das visões de mundo dos educandos.

\section{REFERÊNCIAS}

BARROS, A. M.; GABRIEL, R. Z. Lutas. In: DARIDO, S. C. (Org.). Educação Física escolar: compartilhando experiências. São Paulo: Phorte, 2011.

BAYER, C. O ensino dos desportos coletivos. Lisboa: Dinalivro, 1994.
BECHARA, E. C. Educação Física escolar: proposta para formação de líderes comunitários para alunos de $2^{\mathrm{a}} \mathrm{e}$ $3^{\text {a }}$ séries do Ensino Médio. 2004. 137f. Tese (Doutorado em Educação Física) - Faculdade de Educação Física, Universidade Estadual de Campinas, Campinas, 2004.

BETTI, M.; ZULIANI, L. R. Educação Física escolar: uma proposta de diretrizes pedagógicas. Revista Mackenzie de Educação Física e Esporte, São Paulo, v.1, n.1, p. 73- 81, 2002.

BRACHT, V.; PIRES, R.; GARCIA, S. P.; SOFISTE, A. F. S. A prática pedagógica em Educação Física: a mudança a partir da pesquisa-ação. Revista Brasileira de Ciências do Esporte, Campinas, v. 23, n. 2, p. 9-29, jan. 2002.

BRASIL. Secretaria de Educação Fundamental. Parâmetros Curriculares Nacionais. Educação Física, 3.e 4. ciclos.Brasília: Mec, 1998.

BREDA, M.; GALATTI, L.; SCAGLIA, A. J.; PAES, R. R. Pedagogia do esporte aplicada às lutas. São Paulo: Phorte, 2010.

CARREIRO, E. Lutas. In: DARIDO, S.C.; RANGEL,I.C. Educação Física na escola: implicações para a prática pedagógica. Rio de Janeiro: Guanabara Koogan, 2005, p.244-261.

CORREIA, W. R.; FRANCHINI, E. Produção acadêmica em lutas, artes marciais e esportes de combate. Motriz, Rio Claro, v. 16, n. 1, p.1-9, jan./mar. 2010.

DARIDO, S. C.; GALVÃO, Z.; FERREIRA, L. A.; FIORIN, G. Educação Física no ensino médio: reflexões e ações. Motriz, Rio Claro, v.5, n.2, p.138.145, 1999.

DEL VECCHIO, F. B.; FRANCHINI, E. Lutas, artes marciais e esportes de combate: possibilidades, experiências 
e abordagens no currículo da Educação Física. In: SOUZA NETO, S.; HUNGER, D. Formação profissional em Educação Física: estudos e pesquisas. Rio Claro: Biblioética, 2006.

DRIGO, A. J. O judô; do modelo artesanal ao modelo científico: um estudo sobre as lutas, formação profissional e construção do Habitus. 2007. $310 f$. Tese (Doutorado em Educação Física) - Faculdade de Educação Física. Universidade Estadual de Campinas, Campinas, 2007.

ESPARTERO, J. C. Aproximación históricoconceptual a los deportes de lucha. In: VILLAMÓN, M. Introducción al Judo. Barcelona: Editorial hispano Europea S.A., 1999.

FORQUIN, J. C. Escola e cultura: as bases sociais e epistemológicas do conhecimento escolar. Porto Alegre: Artes Médicas, 1993.

GOMES, M. S. P.; MORATO, M. P.; DUARTE, E.; ALMEIDA, J. J. G. Ensino das lutas: dos princípios condicionais aos grupos situacionais. Movimento, Porto Alegre, v. 16, n. 2, p. 207 - 227, abr./jun. 2010.

GOMES, M. S. P. Procedimentos pedagógicos para o ensino das lutas: contextos e possibilidades. 2008. $139 f$.

Dissertação (Mestrado em Educação Física) - Faculdade de Educação Física. Universidade Estadual de Campinas, Campinas, 2008.

GONZÁLEZ, F. J.; FENSTERSEIFER, P. E. Entre o "não mais" e o "ainda não": pensando saídas para o não-lugar da EF Escolar II. Cadernos de Formação RBCE, Florianópolis, v. 1, n. 2, p. 10 21, mar. 2010.

MAZZEI, L. Cultura e Modelo Organizacionais da Federação de
Judô do Estado do Rio de Janeiro. 2006. Dissertação (Mestrado) - Faculdade de Ciências do Desporto e de Educação Física, Universidade do Porto, Porto 2006.

NASCIMENTO, P. R. B. Organização e Trato Pedagógico do Conteúdo de Lutas na Educação Física escolar. Motrivivência, Florianópolis, v. 20, n. 31, p.36-49, dez. 2008.

NASCIMENTO, P. R. B; ALMEIDA, L. A tematização das lutas na Educação Física Escolar: restrições e possibilidades. Movimento, Porto Alegre, v. 13, n. 03, p. 91-110, setembro/dezembro de 2007. OLIVIER, J. C. Das brigas aos jogos com regras: enfrentando a indisciplina na escola. Artmed, Porto Alegre, 2000.

PAIVA, L. Pronto pra guerra: preparação física específica para luta \& superação. Manaus: OMP Ed. 2009.

PALMA FILHO, J. C. Cidadania e Educação. Caderno de Pesquisa, São Paulo, v. 104, p.101-121, 1998.

PERNAMBUCO (Estado). Secretaria de Educação. Orientações teóricometodológicas: Ensino Fundamental, Educação Física. Recife, 2008.

RANGEL - BETTI, I. C. A. Esporte na escola: mas é só isso, professor? Motriz, Rio Claro, v.1, n.1, jun. p.25-31, 1995.

RUFINO, L. G. B. A pedagogia das lutas: caminhos e possibilidades. Jundiaí: Paco Editorial, 2012a.

RUFINO, L. G. B. "Campos de luta": o processo de construção coletiva de um livro didático na Educação Física no Ensino Médio. 2012. 364f. Dissertação (Mestrado em Desenvolvimento Humano e Tecnologias). Instituto de Biociências. Universidade Estadual Paulista, Rio Claro, 2012 b. 
RUFINO, L. G. B.; DARIDO, S. C. A separação dos conteúdos das "lutas" dos "esportes" na Educação Física escolar: necessidade ou tradição? Pensar a Prática, Goiânia, v. 14, n. 3, p. 117, set./dez. 2011.

RUFINO, L. G. B.; DARIDO, S. C. Possíveis diálogos entre a Educação Física escolar e o conteúdo das lutas na perspectiva da cultura corporal. Conexões, Campinas, v. 11, n. 1, p. 145-170, jan./jun. 2013.
SÃO PAULO (Estado) Secretaria de Educação do Estado de São Paulo. Proposta Curricular de Educação Física. São Paulo: SEE, 2008.

SOARES, C. L.; TAFFAREL, C. N. Z.; VARJAL, E.; CASTELLANI FILHO, L.; ESCOBAR, M. O.; BRACHT, V. Metodologia do ensino da educação física. São Paulo: Cortez, 1992. THOMAS, J. R.; NELSON, J. K.; SILVERMAN, S. J. Métodos de pesquisa em atividade física. Porto Alegre: Artmed, 2007.

FIGHTS CONTENT IN ELEMENTARY SCHOOL'S EARLY GRADES: pedagogical practice possibilities in School Physical Education

\begin{abstract}
Fights are Physical Education contents that should be present in pedagogical practice. However, there are still gaps and misunderstandings in their educational development. Thus, through a literature review, this study aimed to analyze fights as contents of School Physical Education, comprehending its importance as well as presenting a classification form. In a second moment, we presented a curricular organization proposal of fights in elementary school's early grades. We concluded that is important to understand fights as School Physical Education contents. In this way, the content organization suggested can contribute to the critical appropriation of this movement body culture manifestation.
\end{abstract}

Keywords: Fights; Pedagogical Practice; Content's organization.

Recebido em: agosto/2013 Aprovado em: novembro/2013 